\title{
Pathways to music exploration in a digital age
}

\author{
Steven J. Tepper ${ }^{\mathrm{a}, *}$, Eszter Hargittai ${ }^{\mathrm{b}}$ \\ ${ }^{a}$ Department of Sociology, Garland Hall, Vanderbilt University, Nashville, TN 37212, United States \\ ${ }^{\mathrm{b}}$ Department of Communication Studies, 2240 Campus Drive, Evanston, IL 60208, United States
}

Available online 29 April 2009

\begin{abstract}
This paper looks at the largely unexplored terrain of how young people find music that is new to them in an environment with an unprecedented number of possibilities. Digital media has changed not only how artists create and distribute content, but also how listeners find and access new material. The new options exist in the context of older traditions such as using one's social networks or traditional media to find content. Based on original data with a sample of college students, we find that while students use digital media to find music new to them, social networks and traditional media continue to play a very important role in the course of exploration. We also find that digital technology is used differently by different types of music consumers and draw distinctions between peer-to-peer services and browsing, with the former more likely to be used by students from higher socio-economic backgrounds who are opinion leaders in the realm of music. We conclude with observations about the nature of opinion leadership and music and argue that future research should examine more closely the links among the discovery and sharing of culture, opinion leadership and social recognition and status.
\end{abstract}

(C) 2009 Elsevier B.V. All rights reserved.

\section{Introduction}

Changes in culture are intricately connected to changes in technology (Carey, 1988). Throughout history, new inventions in the way sounds, images and texts are produced and captured have changed the way that artists and writers work, leading to new styles (dime novels, impressionism, rock and roll) and forms of expression (photography, synthesized music, digital art). But perhaps even more far reaching, new technologies have dramatically changed the market for art and culture, typically leading to expanded audiences having access to more diverse options. In short, technological change has often accompanied both the expansion and diffusion of culture, facilitating more choices available to more people. Yet, we know little about how new options may have changed the processes people use to expand their repertoire of cultural consumption. This paper looks at pathways to music exploration in an environment that offers numerous choices for discovery.

* Corresponding author.

E-mail address: steven.j.tepper@vanderbilt.edu (S.J. Tepper). 
In recent years, thanks to the increasing spread of digital media, it has become easier for new creators to enter the marketplace with their creations, and consumers of cultural products have access to a larger selection of creative content than ever before. Technology has shifted inventories of music, books, and videos first from expensive physical shelf space in local stores to cheap space in national warehouses, and then to virtual shelf space in the online world. In the purely physical world, the average Wal-Mart store offers around $4000 \mathrm{CD}$ titles and the average music superstore offers 40,000 (Anderson, 2006). Online retailers such as Amazon, on the other hand, offer upwards of 150,000 unique CDs. Digital storefronts like iTunes, Napster, Rhapsody and MusicMatch offer, together, upwards of three million unique tracks available for download.

This paper considers the impact of new digital technology on music consumption, a subject that has drawn considerable attention from pundits, scholars, legal experts, and the music industry. The terrain is contested, messy and difficult to sort out. Traditional social and economic arrangements surrounding intellectual property are breaking down. Business models are shifting daily, and markets are becoming more consolidated. Consumers are facing a mind-boggling array of gadgets and services that allow them to access and enjoy art and entertainment in novel ways. In the face of such a daunting set of issues, we are going to focus on just a small part of the puzzle: How do college students - who are both heavy consumers of music and of technology - go about finding new music ${ }^{1}$ in a digital age?

Why do we care about the discovery of new music? Is there an a priori reason to favor "discovery" in art? Should we care if people prefer to listen to the same Beatles album day-afterday or to a country music station that plays the same 15 songs every $3 \mathrm{~h}$ ? There are two reasons why a healthy art system requires its audiences and consumers to seek out new artists and new sounds. First, innovation and creativity require churn. If demand is sated, and audiences are complacent, then there is little room for new artists and styles to break through. Second, ever since the British economist, Nassau Senior, introduced the "Law of Variety," arguing that "our desires do not aim so much at quantity as diversity" (as cited in Jackson, 1984, p. 8.), economists and psychologists have explored "variety-seeking" behavior in consumers (Tian et al., 2001; McCracken, 1990; Hirschman, 1980). They have concluded that pleasure is derived from the act of stimulating choice, within limits, and discovering something new that satisfies one's preferences. ${ }^{2}$ Musicologists, music theorists and cognitive scientists, of course, have long argued that variety, surprise, and the resolution of the unfamiliar are critical for enjoyment and deep appreciation of music (Hagendoor, 2003; McClary, 1987). Therefore, we can assume that there are positive benefits, for artists, for audiences, and for the larger society, when people sample and explore new art.

Beyond the production of innovative art and the quality of individual experiences, discovery in culture is a key, if under recognized, source of social currency. Discovery plays a role in facilitating friendships and relationships. When we share something new - whether making a mixed CD for a friend, recommending a movie to a colleague, or lending a book to a family member - we forge shared interests, develop reciprocity and trust, and facilitate conversation (Kotarba, 2002; Finnegan, 1989; Erickson, 1996).

Discovery is also linked to status and prestige. It is widely accepted in sociology that cultural consumption serves as a means of distinction and that liking the right type of culture can bring status

\footnotetext{
${ }^{1}$ Here and throughout the paper, when we refer to "new music" we mean music that is new to listeners - e.g., music that does not fall within the category or genre of music to which they typically listen.

${ }^{2}$ Here we emphasize "within limits", acknowledging Schwartz's (2004, 2008) argument that too much choice, generally and with reference to culture, can decrease individual wellbeing by causing regret, anxiety, failed expectations and self-blame.
} 
and prestige, while liking or consuming the wrong culture can signal lower status. Bourdieu (1977, 1984) referred to advantageous culture as "cultural capital," comprised of "high brow" tastes and a disposition and way of talking about culture that signals membership in the professional and upper classes. Cultural capital is often measured as knowledge about and preference for certain styles of art and culture - classical music, ballet, serious literature, opera, and fine art. Measuring cultural capital in this way, however, leaves little room for innovation in the consumption of culture. Status is acquired, for the most part, by liking things that have already been recognized and legitimated as "high culture," whether by museums, music critics, universities or other arbiters of taste. But, can discovering new culture also bring a person status and prestige? Are there any social advantages to being an innovative cultural consumer? Sociologists have largely ignored this question with the exception of a few studies that investigate fashion cycles and demonstrate that high status individuals continuously look to stay ahead of the "fashion curve" in order to maintain their upper hand in the face of "imitators" from lower social categories (Summers, 1970; Crane, 1999). When Prada purses become accessible to the masses, elites look for new brands and new styles to maintain sartorial boundaries and a sense of distinction. Outside of sociology, scholars who study the diffusion of innovation as well as those in the field of marketing science have found that "innovators" - people who adopt new products - tend to come from the professional classes, have higher levels of education, and more often live in cities (Corey, 1971; Rogers, 1995; Chan and Misra, 1990). Discovery and social status appear to be linked.

Second, even though most empirical work on status and culture has focused on the correspondence between the content of people's preferences - what they say they like - and their status, Bourdieu's theory of cultural capital actually emphasizes what people do with culture, not just what they like or know. In other words, how do people use culture in conversation? How do they talk about a painting on a wall or a sonnet or an aria? Holt (1997) argues that research on cultural capital should rely less on "cultural content and more on consumption practice" (quoted in Sullivan and Katz-Gerro, 2007, p. 124). Likewise, simply expanding one's cultural portfolio by discovering new music may not be as important as actively sharing those discoveries with others. In other words, it is not just knowing the right culture, or even knowing "new" culture, but rather knowing things that others would also like to know about. By acquiring new knowledge that others find useful, people can secure status and prestige. In short, they can become opinion leaders in culture (Ruvio and Shoham, 2007).

The literature distinguishes between general market mavens - people who know a lot about many different consumer products and share that information on a regular basis with friends and colleagues - and opinion leaders, who tend to develop expertise in a particular domain - music, food, cars, politics, or health (Feick and Price, 1987; Clark and Goldsmith, 2005). In this paper, we use these terms interchangeably. Opinion leaders and mavens tend to be "innovators," also known as early adopters (Myers and Robertson, 1972; Summers, 1970; Rogers, 1995; Flynn et al., 1996; Goldsmith et al., 2003). Discovery is a key aspect of opinion leadership in culture; and opinion leaders tend to have higher status and be well respected in their communities and by their peers. While it is hard to tease out the direction of causality - do people look to high status peers for their opinions or does becoming an "opinion leader" bring high status - scholars suggest that opinion leaders are well-regarded in part because they play an important social and economic role - they pass on valuable information that improves the wellbeing of people around them (Chan and Misra, 1990; Gatignon and Robertson, 1985; Robertson et al., 1984; Engel et al., 1968; Rogers, 1995).

Finally, over the last decade, scholars have challenged the notion that status is linked to exclusive tastes. Recent scholarship has found that status is increasingly connected not with "high brow" snobbery, but rather with omnivorous tastes; that is, elites show their distinction by 
consuming a great variety of different types of art and culture and by being eclectic and cosmopolitan in their cultural choices (Peterson and Kern, 1996; Peterson and Simkus, 1992; Emmison, 2003; Ollivier et al., 2008). The omnivore thesis has been supported, refined and critiqued by dozens of scholars over the last two decades (Katz-Gerro, 2006; Han, 2003; Van Rees et al., 1999; Bryson, 1997; Warde et al., 1999; Warde et al., 2008; Bellavance, 2008). People disagree on whether omnivorousness has replaced elite forms of cultural capital, or whether omnivorousness is simply an additional form; high status individuals now need to know both the right kind of culture as well as a variety of other cultural styles and forms. And while elites may not actually like this other culture, passing knowledge of diverse music, art and food is necessary in order to appear tolerant and cosmopolitan. Some contend that omnivorousness is tied less to status and more to the strategies of economic agents who increasingly must negotiate a multicultural, global marketplace (Emmison, 2003; Van Eijck, 2000; Erickson, 1996; Lizardo, 2005). Knowing about bhangra, classical music, jazz, and glamour punk can help a manager in an international media firm interact with programmers in India, board members in New York City, investors from New Orleans, and newly hired college graduates. Still others have discussed omnivorousness as the product of a post-modern world, where individuals "code switch" and put on different identities, depending on the context (DiMaggio, 1987; Wynne and O'Connor, 1998). Knowing about a lot of different cultures and having diverse tastes provides people with a greater range of choices when switching and trying on new identities. Regardless, there are distinct social advantages to having broad tastes or broad knowledge about diverse cultural offerings. While there is little direct evidence that omnivorous individuals are also innovators and opinion leaders, the capacity and disposition to discover new music certainly facilitates a diverse and eclectic musical palette. For all of the reasons noted above, the ability and disposition to "discover" new music is likely related to cultural capital, opinion leadership and social distinction.

Prior to the digital revolution, discovering new music required an array of resources. Two decades ago, the expense and time required to discover new artists, especially for young people, was considerable. Music "mavens" often had to own their own cars and had to travel regularly to innercity neighborhoods to patronize record stores that were off the beaten path. They invested significant sums buying dozens of albums every year in search of new unfamiliar artists. These "opinion leaders" and discoverers had to rely on broad social networks - family and friends living in other cities and countries, who would regularly send them music that was not available locally. They would have also spent time and money listening to new local bands in music clubs in the city. And, they would have subscribed to high-priced magazines like The Wire, ${ }^{3}$ where they searched for reviews of non-mainstream, cutting edge artists. In part because of issues of access and expense, past music mavens and opinion leaders have tended to come from the ranks of the elite.

In theory, the digital revolution and the arrival of new technologies should democratize the discovery of new music and the capacity for individuals to become opinion leaders in culture. More people have access to a greater variety of culture than ever before. The digital divide creates new inequalities, but as this divide closes, as some commentators contend that it will, more citizens will be able to discover new music through a variety of online services. If discovery and opinion leadership are sources of status, then new technology might serve to flatten hierarchies and cultural advantage. It is beyond the scope of this paper to sort out the relationship among technology, discovery, opinion leadership and status. But, we can answer the following more descriptive and more limited questions: First, does new technology facilitate discovery of new music for college students? Second, is everybody using new technology to discover new music or just some students?

\footnotetext{
${ }^{3}$ An expensive British magazine for eclectic rock aficionados.
} 
If there are variations in this activity, are there identifiable status differences between users and nonusers? Additionally, are users more likely to be opinion leaders? If so, what are the distinguishing characteristics of opinion leaders in the realm of music exploration? Are such opinion leaders more omnivorous in their tastes? Are they pre-disposed toward experimentation?

In this paper, we will first discuss existing approaches to explaining how audiences and consumers typically discover and make decisions about new products, ideas, and cultural goods. Next, we apply these approaches to the behavior of college students - emphasizing first the general relationship students have to music and second the specific strategies or behaviors that lead them to experiment with new music. Finally, using a unique data set, we take a closer look at the role of new technology, analyzing the factors that are related to its use in the exploration of new music. We also offer a snapshot of the characteristics of those college students who selfidentify as opinion leaders or "mavens" in the realm of music.

\section{Pathways to experimentation}

Scholars offer three general explanations for the behavior and strategies of audiences and consumers. Traditionally, both mainstream media and social networks have been suggested as important pathways in finding out about new products, whether cultural or otherwise. With the recent proliferation of information technology tools, digital media have also garnered attention as important facilitators in this process. This section considers what the literature suggests about the relative importance of these three possible modes of experimentation for college students' musical explorations.

A long tradition of scholarship considers the role of social networks in the process of information seeking. Work in this domain has looked at how people rely on those in their social circles for helping find advice and make purchasing decisions. Social networks disseminate news about jobs, health services, politics and culture (Smith and Christakis, 2008; Lin, 1999; Granovetter, 1995). People regularly rely on friends and acquaintances for recommendations and reviews. As discussed earlier, in the area of art, culture, and media, "opinion leaders," "mavens," and "trendsetters" play a prominent role in the circulation of information about new products (Katz and Lazarsfeld, 1955; Rogers, 1995). In the 1950s, Paul Lazarsfeld first pointed out the important role that "leaders" in a community play in filtering, amplifying and interpreting information and often changing citizen preferences. More recently, Malcolm Gladwell popularized the concept of the "maven," focusing on the diffusion of new cultural trends - for example, a handful of trendsetters in the lower east side in New York City instigated the widespread adoption of Hush Puppies in the late 1990s (Gladwell, 2000). Corporations are increasingly hiring "cool hunters" and mavens to spread the word and create buzz around new products. Consequently, we can expect that exchanges with people in one's networks are important avenues for exploring new music.

In another vein, consumers continue to be confronted by mass media and advertising. Well over a hundred billion dollars are spent each year by the U.S. advertising industry on ads in mainstream media under the assumption that the mass media are a source of influence and information for consumers (TNS Media Intelligence, 2006). Ad agencies continue to perfect the "science of persuasion," convincing American consumers to buy new appliances, try new drinks, and switch cleaning detergents. In recent years, there has been a reaction against the idea that consumers are "dupes" and passive media consumers (Hackley, 2005; Schudson, 1986), as scholars have shown how audiences actively navigate the marketplace, resist dominant media messages, and take advantage of empowering technologies (Rubin, 1994). But some of these claims 
might be overstated and exceedingly optimistic. Neuman (1991) found that the development of cable television and the explosion of cultural choice did not lead to interactive consumers who wandered off the beaten path, chose their own ending to television shows, and posted comments and offered critique through their television sets. Instead, he discovered that audiences are habit bound, and that cultural practices, like watching TV, labor under heavy inertia. People resist new technologies if they challenge existing media habits. He also found that audiences are quite passive when it comes to cultural consumption; they do not want to work hard for their entertainment. Consequently, network television stations maintained a large share of the market for much longer than expected, even in the face of a proliferating number of cable programs. Neuman's work suggests that despite the increasing availability of digital media, adoption rates might be slower than expected and cultural consumers will continue to rely on traditional mass media (radio, television, newspapers, films) as important sources for the discovery of new music.

Information technologies offer tools for users to navigate ever-expanding cultural catalogues (Anderson, 2006). Catalogues of cultural products (e.g., books, music, film) have become much bigger, more diverse, and expansive. Some scholars and pundits adhere to the notion that the sheer size of the new virtual catalogues will incite people to experiment and discover new things (Anderson, 2006). Economists agree that technology leads to new patterns of experimentation, but they focus more narrowly on the "new electronic market place" (Bakos, 1998). Accordingly, they point out that technology has reduced the cost of searching and browsing by enabling consumers to "sample" or "rent" music and books for a short period of time at relatively low cost. No longer do consumers have to buy a whole album only to find out that they like just one song. As Cory Doctorow, former Grateful Dead drummer, proclaims, "The whole point of digital music is the risk-free grazing" (Doctorow, 2003). Based on these arguments, we would expect that technology is a primary tool for students as they seek out new music.

In sum, existing theories about cultural consumption and media use suggest that there are three main ways in which users might find music new to them. First, they may rely on their social networks for recommendations. Second, they may get ideas from exposure to mainstream media. Third, thanks to an ever-increasing slate of technological innovations, they may find suggestions through digital media. And while these methods are not mutually exclusive, nor do they account for all possible ways in which one might come across new music, most methods do fall into one of these three distinct categories.

If technology is a popular tool for discovering music, what explains why some students are more likely to use new technology than others? There are several approaches in considering the adoption and diffusion of technology. First, some scholars believe that inherent qualities of a technology will determine how it is used. In particular, new technologies will eventually diffuse and be employed in ways that maximize their capacities. An example of this argument is that if computers allow people to circulate information without making paper copies, then paper will slowly disappear from the workplace. Similarly, if new technology makes it easier to search for and find new music, people will eventually use it precisely in this way. While diffusion might be inevitable, "transaction costs" might slow widespread adoption. In other words, there are costs associated with the use of new technology - both the cost of the technology itself and the extra time and energy necessary to learn how to use it efficiently. Since most college students have access on their campuses to computers, software and high-speed Internet, we do not think "ability to pay" will be significantly related to technology use. On the other hand, skill or familiarity with the Internet might lower the "transaction costs" for some students. Thus, we believe that students who are heavy Web users, an imperfect proxy for familiarity with Internet services, will be more likely to use new technology to explore music than those who are less 
active online. Also, heavy Web use should be positively related to the use of technology for discovering new music because students who spend more time online are likely to spend some of those many hours exploring and consuming music.

A second approach to predicting the adoption of new technology is to consider the interests and habits of consumers. Here, instead of assuming technology will naturally diffuse broadly to the public, we see technology as a tool that is employed by individuals to pursue or support their existing habits, interests and predilections. Fischer (1992) has demonstrated that the telephone was initially used by women as a means to facilitate the types of social gatherings and interactions that were important to them. It did not replace face-to-face conversation, it simply made it easier to plan and carry out such interaction. This approach would suggest that students who are already heavily invested in consuming music - they listen to lots of music or lots of different artists - will be more likely to use new technology to supplement and enrich their musical lives.

A third approach is to consider the disposition of potential users. Everett Rogers suggests that the earliest adopters of technology (what he calls innovators) tend to be "venturesome" - they are eager to try new ideas (Rogers, 1995). Thus, we predict that those students who say that they are actively searching for new music (what we refer to above as "those who seek out variety") will be more likely to use new technology for this purpose.

Rogers also suggests that early adopters are likely to be opinion leaders or what some refer to as mavens; these are people who make recommendations and give out advice and information on a regular basis. Such individuals have an incentive to use new technology because their reputations and identities depend in part on being "in the know" and having access to new music and providing a continuous flow of suggestions to friends and colleagues. New technology gives these mavens unprecedented accesses to new music - and we expect them, more than others, to take advantage of this new tool.

How important are the three modes of exploration relative to each other and who is most likely to use digital media? Finally, what role do "opinion leaders" play in this process and what is the relationship between discovery of music, opinion leadership and status? The following section describes the data we use to answer these questions.

\section{Data and methods}

To explore the questions outlined above, we conducted a survey of how college students learn about new cultural products with a section focusing specifically on musical interests. It is that part of the data set that we analyze here. We administered a paper-pencil questionnaire in 2003-2005 to students enrolled in sociology and communication courses on three different college campuses across the United States (one in the Northeast, one in the Midwest, and one in the South). ${ }^{4}$ While the use of digital media changes from year to year, we believe it is extremely important to capture how services are adopted in the initial years of the availability of new technologies. The sample consists of 328 students with close-to-equal representation of different class years (23\% first years, 33\% sophomores, $23 \%$ juniors and $22 \%$ seniors). A little more than half $(57.5 \%)$ are female with the average respondent 20 years of age (standard deviation: 1.4; only students 27 and younger are included in this study).

\footnotetext{
${ }^{4}$ The courses were open to non-majors and attracted students from across the disciplines. Nonetheless, the number of students interested in sociology and communications is certainly over-represented. This may caution against over generalizing our findings; but we have no a priori reason to believe that these students will use technology in ways that are substantially different from their peers.
} 
Table 1

Ways in which students find music new to them, ranked in order of popularity ${ }^{\mathrm{a}}$. SN, social network; TM, traditional media; IT, info technology $(N=328)$.

\begin{tabular}{|c|c|c|c|}
\hline & $\begin{array}{l}\text { Number of } \\
\text { mentions }\end{array}$ & $\%$ & Type \\
\hline A personal acquaintance played me the song/album/artist & 179 & .54 & SN \\
\hline Listening to a radio station (offline) that I frequently listen to & 130 & .40 & TM \\
\hline A personal acquaintance recommended the song/album/artist to me & 124 & .38 & $\mathrm{SN}$ \\
\hline Watching a music video on television (e.g., MTV) & 87 & .26 & $\mathrm{TM}$ \\
\hline Using a peer-to-peer (P2P) file-sharing network & 66 & .20 & IT \\
\hline Watching a film in which the song/artist was featured as part of the sound track & 66 & .20 & $\mathrm{TM}$ \\
\hline Browsing through multiple radio stations (offline) & 55 & .17 & $\mathrm{TM}$ \\
\hline A personal acquaintance made me a $\mathrm{CD} /$ tape compilation & 46 & .14 & $\mathrm{SN}$ \\
\hline A personal acquaintance sent me the song(s) via the Internet & 44 & .13 & SN \\
\hline Browsing a subscription music library online (e.g., MP3.com or iTunes) & 28 & .09 & IT \\
\hline Browsing the Internet (not an online radio station or music library or online store) & 26 & .08 & IT \\
\hline I read about the song/album/artist in a printed newspaper/magazine & 25 & .08 & $\mathrm{TM}$ \\
\hline A personal acquaintance lent me a disk or recording of the song/album/artist & 22 & .07 & $\mathrm{SN}$ \\
\hline I read about the song/album/artist in an online newspaper or magazine & 18 & .05 & IT \\
\hline Listening to live radio online & 10 & .03 & IT \\
\hline $\begin{array}{l}\text { A personal acquaintance pointed me to a site on the Internet where } \\
\text { the song(s) was available }\end{array}$ & 8 & .02 & $\mathrm{SN}$ \\
\hline $\begin{array}{l}\text { Listening to a free online service that provides access to multiple } \\
\text { genres and types of music (Netscape Radio, etc.) }\end{array}$ & 8 & .02 & IT \\
\hline Watching a music video on the Internet & 5 & .02 & IT \\
\hline I read about the song/album/artist on a blog or discussion forum & 5 & .02 & IT \\
\hline A personal acquaintance bought me the song/album/artist as a gift & 4 & .01 & SN \\
\hline $\begin{array}{l}\text { Referred to the song(s)/artist by an online service (a service that tries to match } \\
\text { recommendations to a user-profile/preference-profile that you provide, } \\
\text { e.g., Netscape Radio, Launchcast) }\end{array}$ & 3 & .01 & IT \\
\hline An employee of a music store recommended the song/album/artist to me & 0 & & N/A \\
\hline
\end{tabular}

\footnotetext{
a Participants were asked to rank their top three preferences in response to this question: "In general (not specific to any particular song/CD/album), when you try something new or different (that is, a song or artist that does not fall within the category of music you "typically listen to"), how do you typically find out about such music?" This table reports aggregates where any ranking of the response was coded as a means of access.
}

All three schools in the sample are selective private institutions, which has to be kept in mind when trying to generalize from the findings. However, the fact that respondents represent aboveaverage socio-economic backgrounds (the average parent has above college education) is ideal for this study, because it suggests that these students have at their disposal all sorts of consumer electronics, online services and cultural products that may be less available to others. ${ }^{5}$ By controlling for access to a range of services and options for cultural consumption, we can focus on usage preferences without having to be concerned about access differences. While controlling for access, we can examine differences in the economic background of students - whose socioeconomic status might still influence their disposition or capacity to use new technology as well as whether they self-identify as opinion leaders or mavens. Across the three institutions, there is variation in the education levels of students' parents, a proxy we use for socioeconomic status.

\footnotetext{
${ }^{5}$ Moreover, given that some previous work has found that people from lower income backgrounds may be more likely to form high attachment to certain traditional media, it is additionally helpful to control for the easy availability of various options (Grant et al., 1991; Loges and Ball-Rokeach, 1993; Ruggiero, 2000).
} 
We also find that the sample has considerable IT experiences. On average, these students had been Internet users for eight years by the time of the study and had had a cell phone for four years when they took the survey. Also, on average, they spend $23 \mathrm{~h}$ online each week.

Of course, it is difficult to generalize from college students to the rest of the population, but students are a good weather vane for larger currents in the world of music. Music labels have largely targeted college students as prime suspects in the illegal downloading of music (BBC News, 2006). College radio stations play an important role in promoting diverse and "alternative" music. College students are frequent early adopters of new technology, as evidenced by the flood of iPods on campuses before their mass diffusion among the population at large. Finally, music is a particularly important source of identity and social currency for young adults (Epstein, 1998; Bennett, 2000). In short, if new technologies are influencing patterns of musical consumption, we would expect college students to be at the forefront of such changes.

\subsection{Dependent variable}

\subsubsection{Finding new music}

The questionnaire included an elaborate list of items concerning the ways in which students find music that is new to them. The questionnaire asked: "In general, when you try something new or different (that is, a song or artist that does not fall within the category of music you 'typically listen to'), how do you typically find out about such music?" Students were given 22 possible response categories (see Table 1). Each category - or means of finding new music - was subsequently coded into technology, traditional media, and social networks; these designations are listed in Table 1 as well. In the case of identifying whether a student employs one of these three methods to find new music, we use a dummy variable (e.g., if students identify technology as a first, second or third choice; they are considered a technology user; otherwise they are coded as '0.')

\subsection{Independent variables}

\subsubsection{Musical habits}

We also asked students about their current musical preferences and habits. We asked them to check all genres (alternative and hard rock; dance and electronica, Country, etc.) and subgenres (Classic Punk; Techno; Americana) that they listen to most regularly. We created an omnivore variable which measures whether a respondent chose a genre or subgenre across the following three categories - alternative and hard rock; classical; and Latin. These three genres represent very different musical traditions; therefore we consider the $22 \%$ of respondents who chose all three to have fairly diverse and eclectic tastes. ${ }^{6}$ We also asked students to indicate "the number of hours per week" they spend listening to music, called hours of music; and "how many different artists or bands" they listen to in a given week, called number of artists. Both variables are ordinal

\footnotetext{
${ }^{6}$ We chose these three genres for methodological and theoretical reasons. First, all three genres were listened to by at least one-third of the sample. This guaranteed that there were a sufficient number of students who liked all three genres. Using less mainstream genres in our omnivore measure - such as blue grass - produced a much more selective definition of omnivore. We were interested in students with diverse tastes, but not necessarily those who have diverse and extremely rare tastes. Substantively, the three genres represent very different musical formats with little crossover (unlike pop and country or rock and blues or jazz and classical). And, while one reviewer was concerned that including Latin in the measure would conflate omnivore with ethnicity, there were very few Hispanics in our sample based on the demographics of the three institutions from which the sample was drawn. We did try the omnivore measure with different mixes of genres and, in most cases, found that the results were similar.
} 
variables, with hours of music measured as less than $3 \mathrm{~h}, 3-10 \mathrm{~h}$; 11-20 h; and more than $20 \mathrm{~h}$; and number of artists measured as less than 6 artists, 6-10 artists, 11-15 artists; and more than 15 artists. Number of artists is a measure of the total number of different artists while omnivore is a measure of preference across multiple genres.

In terms of opinion leadership in music, we asked students whether they consider themselves "mavens" defined in the survey as "someone who frequently makes recommendations to others regarding new music." Existing literature suggests a maven is a generalist who shares information with others about a variety of products (Price et al., 1995). Mavens are often interested in "good value" and "low prices" and are not necessarily committed to novelty. What we call maven is closer to what scholars refer to as "opinion leaders" - people with expertise in a particular domain - e.g., music - who tend to introduce new products or ideas to friends, family and colleagues. In subsequent analyses, we measure top maven as someone who makes recommendations to five or more people on a regular basis (represented by $16 \%$ of the sample). Near the end of the paper, we examine the characteristics of opinion leaders (top maven). As part of this analysis we look at whether opinion leaders (those students who frequently recommend music to other people) are also opinion receivers or recipients of recommendations, measured as a binary variable indicating whether or not a respondent receives recommendations for new music from five or more people on a regular basis. Finally, we measure a students' disposition for discovery (experimenter) through a question that asked whether they consider themselves to be someone who actively searches for new things to try (see detailed description in next section).

\subsubsection{Time spent online}

In order to get a rough approximation of familiarity with and preference for using the Web, we use an ordinal variable for weekly time spent online (not including email and chat use), represented by three categories - less than $3 \mathrm{~h} ; 3-10 \mathrm{~h}$; and more than $10 \mathrm{~h}$.

\subsubsection{Demographics and SES}

In addition to controlling for gender, we measure socio-economic status in two ways. Parent's education is an ordinal variable designating whether or not a student's parents (between them) have (1) no college education; (2) at least one college degree; (3) two college degrees; and (4) at least one graduate degree. Given the sample size and issues of confidentiality, we were not able to ask about race and ethnicity on our survey.

Finally, in addition to the variables listed above, we control for the student's institution (one of three possible colleges); and we control for their class year (freshman, sophomore, junior or senior).

Below, first we present basic descriptive statistics to gain a better understanding of how important music listening is in students' lives and what are the most popular ways in which they find new music. Then, we use logistic regression analyses to understand what types of listeners are most likely to use various methods and the attributes of "opinion leaders" in the realm of music.

\section{Results and analysis}

\subsection{Music in the lives of college students}

Before looking at the ways in which students find new music, it is important to establish the importance of music in their everyday lives. Regarding our specific questions about how students 


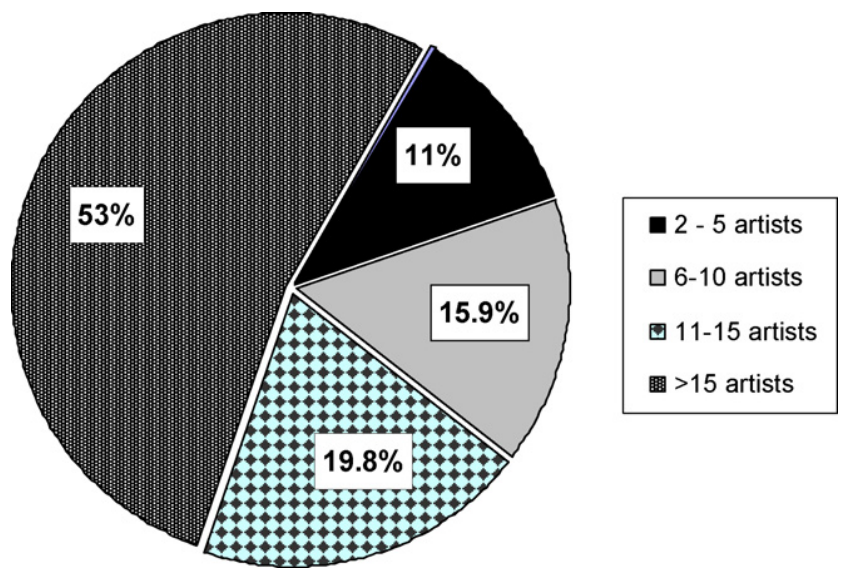

Fig. 1. Number of artists that students listen to in any one week $(N=328)$.

find music new to them, we also need to know how prevalent looking for novel forms of musical entertainment is in their lives. That is, if most students prefer to stick to their tried-andtrue list of artists then the method of exploration is not of nearly as much significance as it is if it turns out that most students do engage in variety-seeking. In this section, we present descriptive statistics about students' music listening, their interest in new music exploration, the most popular ways in which they find music, and the extent to which they tend to make recommendations to others.

As expected, music listening is a popular activity in the lives of college students. When asked about the number of different artists they listen to in a given week - the vast majority ( $89 \%$ ) reported that they listen to at least five different artists a week, and over half (53\%) indicated that they listen to more than 15 different artists (see Fig. 1). Students also listen to music often, with almost half (46.9\%) listening to at least $10 \mathrm{~h}$ a week and one-fifth doing so for more than $20 \mathrm{~h}$ weekly (see Fig. 2).

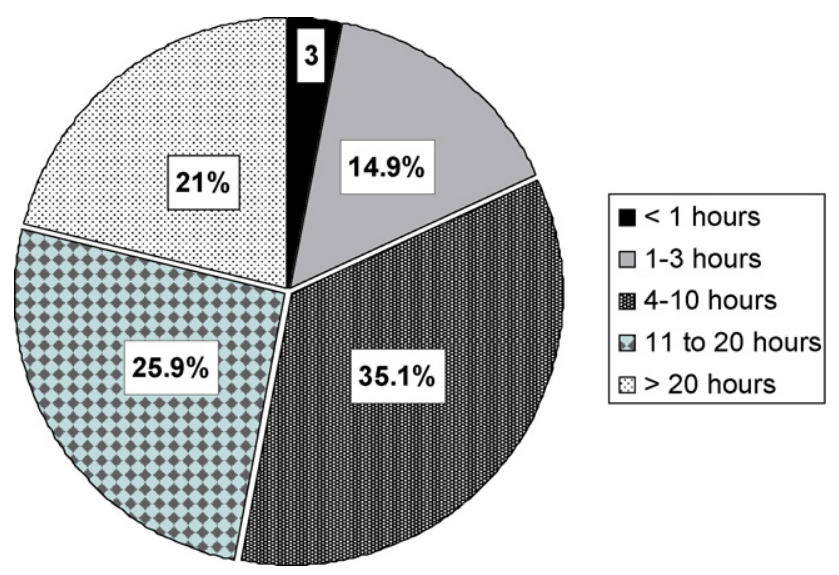

Fig. 2. Number of hours that students listen to in any one week $(N=328)$. 


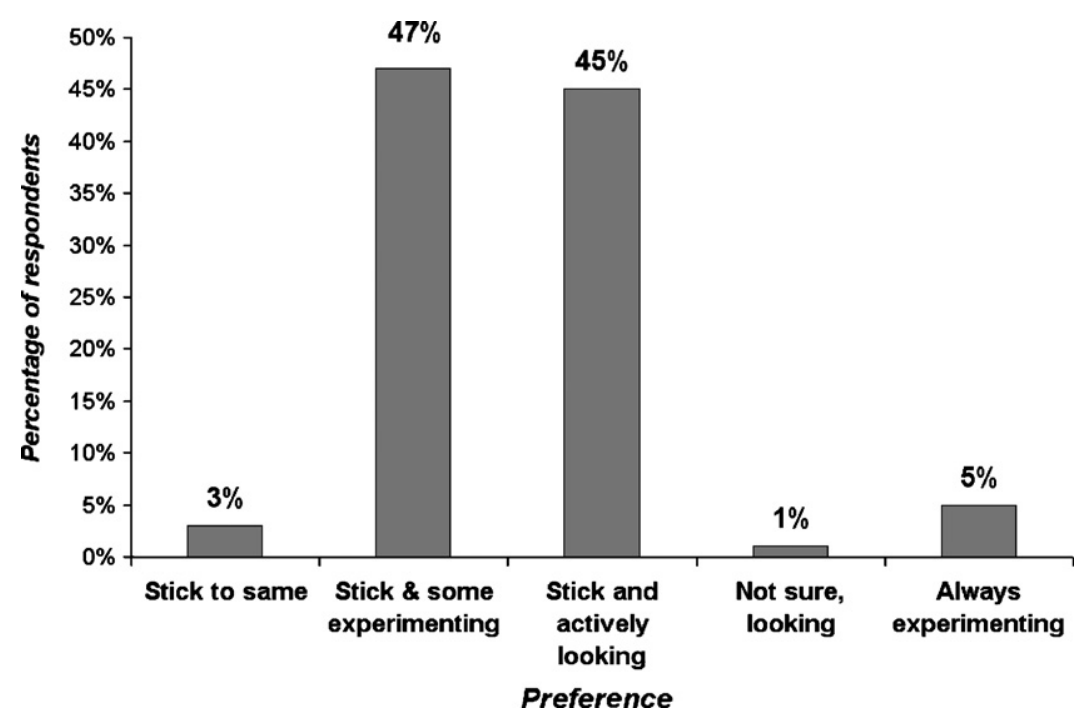

Fig. 3. Students' variety-seeking interest regarding new music $(N=328)$.

To ascertain the level of interest in new music discovery, we asked respondents to tell us about their variety-seeking behavior. Our sample of students was almost evenly divided between two (out of five) statements: $47 \%$ claimed that "I generally stick to music I like and know well and will try new things if others recommend them to me, but I do not actively look for new things" while $45 \%$ said that "I generally stick to music I like and know well, but I am actively looking for new things to try also." (see Fig. 3 for all answer options). We characterize these two groups as those who are "open to variety" and those who "seek out variety." Very few students (3\%) shun variety entirely ("always stick to music I like and know well") and very few (5\%) are always experimenting and trying new things.

We were also interested in identifying how likely people are to make recommendations to others about music. As noted earlier, we asked respondents whether they considered themselves "mavens" defined in the survey question as "someone who frequently makes recommendations to others regarding new music." We included this question to be able to hone in on trendsetters in particular when it comes to more novel means of experimentation. Over twothirds of participants $(68 \%)$ self-identified as a maven. However, the majority claimed to be a maven to no more than four people. Only $16 \%$ indicated making recommendations to five or more people regularly, these people constitute the group of top mavens in our analyses. Finally, as previously noted, $22 \%$ of the respondents - who we designate as omnivores - indicate that they enjoy music across three dissimilar genres - alternative rock, classical and Latin. The average number of different genres (of a possible 17) selected by our respondents is 8.2 , with $43 \%$ of the sample choosing all 5 of the most popular genres - rock, alternative rock, pop, rap and dance.

Overall, it is clear from these descriptive figures that music plays an important role in these college students' everyday lives. Most of them are open to and many of them seek out experimentation in the realm of music listening. They are fully wired, so new opportunities, thanks to innovations in information technologies, are within their reach. Finally, the majority considers itself trendsetters although a smaller number take on this role actively. Next, we look at 
the relative popularity of the various methods for finding new music and whether there are any systematic trends in who is more likely to use digital media for such purposes.

\subsection{Popular methods for finding new music}

Table 1 shows the relative popularity of the various ways in which students report finding music new to them. Respondents were presented with a list of 24 possible items (all listed in the table) and asked to rank their top three most typical methods for finding new music. The figures here are presented in a manner that aggregates data about these top three choices, that is, in this aggregated table a "method" is considered a means of finding new music if the person ranked it as any one of his or her top three choices.

By far, the most common methods either involve relying on recommendations from people in one's social network or on content encountered through traditional media. The most popular method (listed by 54\% of respondents) is finding out about something thanks to a personal acquaintance playing the music to the respondent. A similar method - third in popularity concerns a recommendation from a personal acquaintance, which was listed by $38 \%$ of respondents. The most popular means through traditional media seems to come from listening to a radio station offline ( $40 \%$ indicated this option), with watching a music video chosen by $26 \%$ of the sample. The fifth most popular method is one that concerns digital media: file-sharing is indicated by $20 \%$ of the sample as a top three method for finding new music.

To compare across the three broad approaches to discovering new music, we aggregated the methods into traditional media, social networks and information technologies (see Section 3 for more details). Fig. 4 shows the aggregated numbers both for the top three methods and the topmost method. Here, again, we see that both in terms of aggregated top preferences and the topmost means social networks are the most popular, followed closely by traditional media and information technologies lagging behind considerably. ${ }^{7}$

While people may be relying on digital media tools to share music with their friends and acquaintances, such modes of exploration, without an explicit social component, have not spread widely among our sample of students. For example, only $9 \%$ reported finding new music by browsing a subscription music library. While services like iTunes may be popular in the initial phases of loading one's device with music, once a user has collected songs by artists already known to the listener, such tools are not proving to be popular for expanding one's selection. ${ }^{8}$

\subsection{Explaining technology users}

Although technology ranked behind social networks and mass media as a method for exploring new music, given its role in debates about expanding choice and shifting consumer behavior, we take a closer look at the factors that predict its use.

\footnotetext{
${ }^{7}$ See the column labeled "type" in Table 1 for how we classified each method. Note, we generously classified items as IT if they involved any type of new technology. That is, "I read about the song/album/artist in an online newspaper or magazine" is coded as an IT type method even though it could also be considered a traditional medium if the site is simply the online manifestation of an established mainstream medium. Coding that variable as "traditional media" changes the results only slightly.

${ }^{8}$ It is important to note that the study was conducted in 2003-2005. It is possible that certain information technology services - like subscription libraries - have become more popular with college students. But, most of the technologies identified in Table 1 were reasonably well-established by the time of the survey, so the findings, we believe are still applicable in today's media and technology environment.
} 


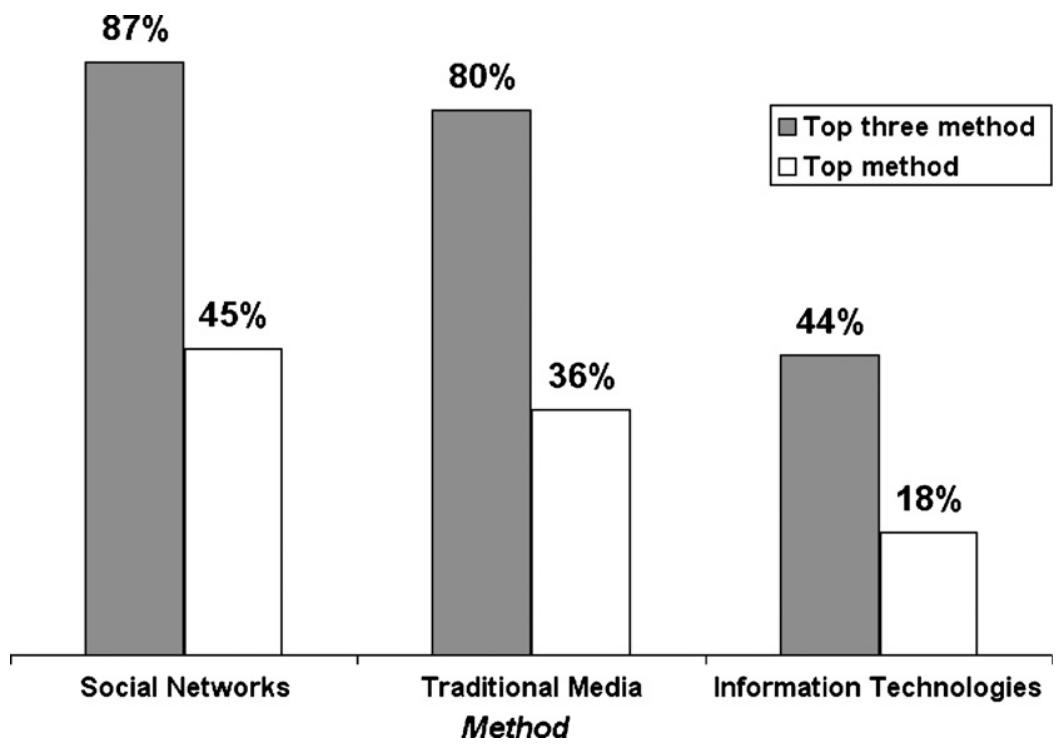

Fig. 4. Finding new music: comparing social networks, traditional media and information technology $(N=328)$.

In our analysis, we use logistic regression to look at the predictive power of several key variables; gender and socio-economic status; Internet user experience; and musical habits, including opinion leadership. We also control for institution (where the survey was administered) and the class year of the respondent. In addition to technology, we also examine the extent to which our key variables predict social networks and traditional media as preferred methods for discovering new music.

Analysis presented in Table 2 shows only modest differences in what predicts the use of social networks, traditional media and technology. Consistent with the literature on gender and technology use, we find that women are less likely to use technology to discover new music than men (59\% as likely, see column 3) and 2.75 times more likely to use social networks (column 1, see exponentiated coefficients reported in parentheses). Contrary to expectations, respondents who spend more time online (time spent online) are not more likely to use technology to find new music. We do find that, compared to freshman, upperclassman use new technology much less and social networks much more. We suspect this reflects the maturation and development of students' social lives over their college careers.

When we examine musical habits, we find that students who listen to a greater number of artists are more likely to use technology to find new music, while this is not true for social networks or traditional media. This lends some support to the notion that respondents who are heavily invested in music - e.g., they listen to many different artists in a given week - are more likely to be "early adopters" of technology for the purposes of discovering music. ${ }^{9}$ On the other hand, hours of music - also a measure of musical consumption - shows no consistent relationship

\footnotetext{
${ }^{9}$ We cannot claim that listening to many different artists causes people to go online to search for new music. It may be that those who spend time on line searching for music come across new artists. In other words, throughout the analysis there is likely substantial endogeneity between online behavior and musical habits. Given that the data is cross-sectional, we cannot tease out causality.
} 
Table 2

Predictors of using social networks, mass media or technology to find new music $(N=301)^{\mathrm{a}}$, coefficients from logistic regression models (odds ratios appear in parentheses). Numbers appearing in bold are statistically significant.

\begin{tabular}{|c|c|c|c|c|c|}
\hline & $\begin{array}{l}\text { Social } \\
\text { networks }\end{array}$ & $\begin{array}{l}\text { Traditional } \\
\text { media }\end{array}$ & Technology & $\begin{array}{l}\text { Browsing } \\
\text { online }\end{array}$ & $\mathrm{P} 2 \mathrm{P}$ \\
\hline \multicolumn{6}{|l|}{ Background variables } \\
\hline \multicolumn{6}{|l|}{ Freshman (baseline) } \\
\hline Sophomore & $.312(1.37)$ & $-.343(.709)$ & $-.212(.809)$ & $.077(1.08)$ & $.103(1.11)$ \\
\hline Junior & $\mathbf{1 . 3 3}^{* *}(3.79)$ & $-.808^{*}(.446)$ & $-.788^{* *}(.455)$ & $-.147(.863)$ & $-.390(.677)$ \\
\hline Senior & $.137(1.14)$ & $-.338(.713)$ & $-.947^{* *}(.388)$ & $-.428(.652)$ & $-.864(.421)$ \\
\hline Female & $\mathbf{1 . 0 1}^{* * * *}(2.75)$ & $.511(1.667)$ & $-.519^{*}(.595)$ & $-.029(.971)$ & $-.611^{*}(.543)$ \\
\hline \multicolumn{6}{|l|}{ Parent's college education } \\
\hline \multicolumn{6}{|l|}{ No college graduates } \\
\hline One parent is a graduate & $-.139(.87)$ & $.373(1.45)$ & $.170(1.185)$ & $-.475(.622)$ & $.765(2.15)$ \\
\hline Both parents are college & $.822(2.28)$ & $-.417(.659)$ & $.263(1.301)$ & $-.944^{*}(.389)$ & $1.30(3.67)$ \\
\hline Both parents have graduate degrees & $\mathbf{1 . 4 8 9}^{* *}(4.42)$ & $-.373(.689)$ & $-.122(.885)$ & $-\mathbf{1 . 0 5 8}^{*}(.347)$ & $\mathbf{1 . 5 4}^{*}(4.68)$ \\
\hline \multicolumn{6}{|l|}{ Time spent online (weekly) } \\
\hline \multicolumn{6}{|l|}{ 4-10 h (baseline) } \\
\hline$<3 \mathrm{~h}$ & $-.100(.909)$ & $-.504(.604)$ & $.069(1.072)$ & $-.078(.925)$ & $.043(1.04)$ \\
\hline$>10 \mathrm{~h}$ & $-.564(.569)$ & $-.373(.689)$ & $.403(1.50)$ & $.327(1.39)$ &. $\mathbf{7 1 1}^{*}(2.04)$ \\
\hline \multicolumn{6}{|l|}{ Musical habits } \\
\hline \multicolumn{6}{|l|}{ Weekly hours of music } \\
\hline \multicolumn{6}{|l|}{$<3 \mathrm{~h}$ (baseline) } \\
\hline $3-10 \mathrm{~h}$ & $.129(1.14)$ & $-.491(.612)$ & $.692^{*}(1.998)$ & $\mathbf{1 . 2 5 3}^{*}(3.50)$ & $.681(1.98)$ \\
\hline $11-20 \mathrm{~h}$ & $-.407(.666)$ & $-.598(.550)$ & $.682(1.98)$ & $1.74^{* * * *}(5.72)$ & $-.084(.919)$ \\
\hline$>20 \mathrm{~h}$ & $.556(1.74)$ & $-.999(.689)$ & $655(1.91)$ & $1.27^{*}(3.58)$ & $-.161(.851)$ \\
\hline \multicolumn{6}{|l|}{ Number of artists } \\
\hline \multicolumn{6}{|l|}{$<6$ different artists (baseline) } \\
\hline $6-10$ different artists & $.202(1.22)$ & $-.53(.589)$ & $.430(1.54)$ & $.490(1.63)$ & $.537(1.71)$ \\
\hline $11-15$ different artists & $.521(1.68)$ & $-.717(.488)$ & $.967^{*}(2.63)$ & $.424(1.53)$ & $1.32(3.73)$ \\
\hline$>15$ different artists & $-.117(.889)$ & $-.583(.558)$ & $.819^{*}(2.26)$ & $.455(1.50)$ & $1.02(2.77)$ \\
\hline Top maven & $-.945^{*}(.389)$ & $-.078(.925)$ & $-.411(.663)$ & $-\mathbf{1 . 3 0 3}^{* *}(.272)$ & $.801^{*}(2.23)$ \\
\hline Experimenter & $-.183(.8330)$ & $.038(1.04)$ & $.335(1.40)$ & $.356(1.43)$ & $-.240(.787)$ \\
\hline Omnivore & $1.347^{* *}(3.84)$ & $-.917^{* * *}(.400)$ & $.242(1.27)$ & $.110(1.12)$ & $.351(1.41)$ \\
\hline Constant & .722 & 3.23 & -1.208 & -2.39 & -3.48 \\
\hline
\end{tabular}

Others variables controlled for - but not reported in the table - include the institution where the survey was conducted.

a The sample size is reduced by 27 observations due to missing values on the independent variables.

* Significant at the .1 level, two tailed.

** Significant at the .05 level, two tailed.

**** Significant at the .01 level, two tailed.

to music discovery across any of the three strategies. ${ }^{10}$ Opinion leaders - or mavens - again contrary to expectations, do not seem to prefer consistently any of the three strategies for finding new music - technology, social networks, or mass media.

There is one notable difference in terms of musical habits - people who are omnivores (liking multiple genres of music) are 3.8 times more likely to use social networks; in contrast,

\footnotetext{
${ }^{10}$ The lack of significant results for number of artists and hours of music may be due to the fact that our variables do not capture meaningful differences between music listeners. With better measures of musical habits, including perhaps different survey questions that tease out what they do when they listen to music (e.g. back ground music verses intensive listening), we could have more easily differentiated the active and serious listeners from the more casual listeners. Also, we convert these ordinal variables into categorical variables in our analysis for ease of interpretation. When we run the models with number of artists and hours of music as ordinal variables, the results are largely the same.
} 
omnivores are $40 \%$ less likely to use traditional media (columns 1 and 2, Table 2). Explaining this difference is beyond the scope of this paper, but the results suggest that diverse musical tastes are reinforced by social exchange and, perhaps, hindered by heavy use of traditional media. An important finding in the context of the current study is that technology users do not appear to differ from non-technology users in terms of being omnivores or experimenters. Based on this initial evidence, there is not much support for the proposition that those who use new technology to discover music will have an adventurous disposition (experimenters who seek variety) or be opinion leaders (mavens). There is some evidence that students who are more invested in music (number of artists) have a greater likelihood of using technology. To summarize, technology is not the primary way students discover music. Furthermore, the minority of students who use technology are not noticeably different from those who do not with the strong exception that technology users are more likely to be men and more likely to be freshman in college.

Our lack of confirmatory evidence may be due to the fact that we are collapsing considerably different technology uses into one group. To clarify, in the analysis thus far we have classified the following actions as use of new technology: the use of peer-to-peer file-sharing $(20 \%$ of the sample); the use of technology to browse subscription libraries like iTunes (9\%) or browsing the Internet more generally ( $8 \%$ of the sample) in addition to some other less popular options listed in Table 1. These methods, however, represent two considerably different types of activities. On the one hand, peer-to-peer services are more likely to be used to find music with which a person is already familiar, e.g., having heard about it from a friend followed by going online with the goal of downloading the song. On the other hand, browsing online is much less focused and deliberate. People often browse without having a predetermined destination - they may be searching for a new experience rather than something they already know they want. Given these differences, we separate "technology use" into two distinct variables - the first: "peer-topeer;" and the second: "browsing on-line." The fact that there is almost no overlap between these two categories among our respondents also suggests that these are relatively distinct activities.

We created a dummy variable for using IT for peer-to-peer (P2P) file-sharing, but not browsing. We also created a dummy variable for using IT for browsing, but not P2P filesharing. In Models 4 and 5 (see Table 2) we look at predictors of these various IT uses and find a distinct pattern. First, surprisingly, heavy Web users (time spent online) are not significantly more likely to browse the Internet in order to find music. Average web use (4-10 h a week) is the comparison category in Table 2; which means the coefficients should be interpreted as the likelihood that low (less than $4 \mathrm{~h}$ ) or high (more than $10 \mathrm{~h}$ ) Web users will browse or use P2P compared to the middle-range user. ${ }^{11}$ Second, we find that heavy music listeners, those who listen to 11-20 h weekly, are more likely to "browse online" for music than less frequent listeners (see Model 4, column 4 in Table 2). Interestingly, top mavens are considerably less likely to browse the Internet to find new music. People who use the Internet to browse for new music are not, for the most part, opinion leaders when it comes to recommending music to their friends and family.

When we look at peer-to-peer file-sharing, we see a very different pattern. First, heavy Web users (time spent online), while not more likely to browse the Internet in search of new music, are more likely to use peer-to-peer services. This partially confirms the hypothesis that those who use

\footnotetext{
${ }^{11}$ Web use was measured, as indicated earlier, by an ordinal variable. The most frequently cited category was the middle category $-4-10 \mathrm{~h}-$ selected by $38 \%$ of the students.
} 
the Web more often (more experience and more opportunity) are more likely to be early adopters of digital media for music exploration. ${ }^{12}$ It may also suggest that the barriers (skill and Web familiarity) for general online browsing are lower than for peer-to-peer; the latter requires users to download and upload software as well as exchange music files. Being an experimenter, however, displays no relationship with $\mathrm{P} 2 \mathrm{P}$ use. And, importantly, opinion leaders (top mavens) are 2.23 times more likely to use $\mathrm{P} 2 \mathrm{P}$ to find new music compared to those who are not top mavens. This confirms previous research identifying a link between early adopters, consumer innovators and opinion leaders (Rogers, 1995; Baumgarten, 1975).

Online browsing and peer-to-peer searching also differ in terms of the socio-economic status of their respective users. Earlier in the paper, we suggested that the use of technology to find new music might contribute to a democratization of opinion leadership - giving more people an opportunity to discover and share new music, thereby raising their status with peers, classmates and colleagues. But, this does not seem to be the case in our study. Students who have a parent with a graduate degree are more than four times more likely to use P2P than those who come from families where neither parent graduated from college. On the other hand, these students from the most highly educated families are 55\% less likely to browse online (see column 4, Table 2). As opinion leadership is associated with $\mathrm{P} 2 \mathrm{P}$ and not browsing, it appears that technology use might actually reinforces socio-economic barriers, rather than afford more people the opportunity to become influencers and mavens. ${ }^{13}$

\subsection{Opinion leadership}

Other than a greater likelihood to use peer-to-peer services, what else differentiates mavens (opinion leaders) from non-mavens? Consistent with the literature on opinion leadership and market mavens, top mavens are more likely to be heavily invested in their domain of expertise in this case, they listen to a greater number of hours of music in a given week than non-mavens in the sample (see Table 3) (Arthur et al., 2006; Richins and Root-Shaffer, 1988; Bloch and Richins, 1983; Flynn et al., 1996). Mavens are more likely to be "venturesome" or experimenters (actively searching for new music); and, while they do not listen to a greater number of artists, they have more diverse tastes (omnivore) than non-opinion leaders. In fact, they are more than two and one-half times more likely to be an omnivore. Again, these findings confirm that opinion leaders tend to be innovators, experimenters, and variety-seekers (Summers, 1970; Hirschman, 1980; Myers and Robertson, 1972; Robertson and Myers, 1969). Interestingly, although opinion leadership has been linked to economic status in previous research, in our sample this does not seem to be the case. Students whose parents do not have college degrees are no less likely to be mavens than those from more privileged family backgrounds. On the other hand, women in our sample are less likely to be opinion leaders than their male counterparts. This may have to do with broader gender imbalances in political and public life - with women more circumscribed and private about their opinions (Katz and Lazarsfeld, 1955; Burns et al., 2001). On the other hand evidence suggests that gender and "opinion leadership" is domain specific - meaning that

\footnotetext{
${ }^{12}$ Even though we do not have over-time data - which is necessary to identify early adopters from late ones - our study took place relatively early in the cycle of digital online music distribution. Services such as iTunes, Rhapsody, Netscape Radio and other online services and sites were widely available but still relatively new when the data were collected in 2003-2005. Therefore, we consider those students who were using these technologies at the time to explore music to be "early adopters". ${ }^{13}$ The relationship between SES and search strategies might be explained by social isolation. Lower SES students in elite colleges are often less socially integrated on campus - therefore, they might spend less time relying on social networks for new music and more time alone browsing the computer. We thank an anonymous reviewer for this insight.
} 
Table 3

Predictors of top maven $(N=317)$, coefficients from logistic regression models. Number appearing in bold are statistically significant.

\begin{tabular}{|c|c|c|}
\hline & Top maven (S.E.) & Exp B (odds) \\
\hline Female & $-.841^{* * *}(.412)$ & .431 \\
\hline \multicolumn{3}{|l|}{ Parent's college education } \\
\hline \multicolumn{3}{|l|}{ No college graduates } \\
\hline One parent is a graduate & $-.352(.747)$ & .703 \\
\hline Both parents are college graduates & $.039(.684)$ & 1.07 \\
\hline Both parents have graduate degrees & $-.292(.712)$ & .747 \\
\hline \multicolumn{3}{|l|}{ Time spent online (weekly) } \\
\hline \multicolumn{3}{|l|}{$<4 \mathrm{~h}$ (baseline) } \\
\hline $4-10 \mathrm{~h}$ & $.639(.651)$ & 1.89 \\
\hline$>10 \mathrm{~h}$ & $1.01(.653)$ & 2.76 \\
\hline \multicolumn{3}{|l|}{ Weekly hours of music } \\
\hline \multicolumn{3}{|l|}{$<3 \mathrm{~h}$ (baseline) } \\
\hline $3-10 \mathrm{~h}$ & $1.17(1.135)$ & 3.23 \\
\hline $11-20 \mathrm{~h}$ & $1.02(1.15)$ & 2.77 \\
\hline$>20 \mathrm{~h}$ & $\mathbf{2 . 8 1}^{* *}(.93)$ & 16.6 \\
\hline \multicolumn{3}{|l|}{ Number of artists } \\
\hline \multicolumn{3}{|l|}{$<6$ different artists (baseline) } \\
\hline 6-10 different artists & $-.105(.985)$ & .944 \\
\hline 11-20 different artists & $-.458(.956)$ & 632 \\
\hline$>20$ different artists & $-.194(.870)$ & .823 \\
\hline Experimenter & $.930 * *(.439)$ & 2.54 \\
\hline Omnivore & $.992^{* *}(.443)$ & 2.70 \\
\hline Recipient of recommendations & $.825^{*}(.441)$ & 2.28 \\
\hline Constant & -3.89 & \\
\hline
\end{tabular}

\footnotetext{
* Significant at the .1 level, two tailed.

** Significant at the .05 level, two tailed.
}

women exert more influence in some areas of social and cultural life (e.g., health care decisions, fashion, fine arts) and less in others (Upright, 2004; Wood, 2005). Further research might explore why women are less likely to self-identify as opinion leaders in the area of music.

Opinion leaders, as measured in our survey, are also enmeshed in dense social networks, exchanging information about music and culture on a regular basis. In addition to recommending new music to at least five other people on a regular basis, these opinion leaders are more than twice as likely to receive recommendations from at least five other people (see the independent variable recipient of recommendations in Table 3). Like earlier research, this finding confirms that leadership is two way - "people who influence others are themselves influenced by others in the same topic area." (Myers and Robertson, 1972). These leaders are socially active (Summers, 1970; Myers and Robertson, 1972; Chan and Misra, 1990) and they acquire and search for new products that they believe will be useful to others and facilitate future social exchange (Atkin, 1972). Based on the literature on opinion leaders, their reputation is based on connoisseurship, which requires access to a variety of types of music and bands that they know well and feel confident recommending to others. This explains their omnivorous tastes; it also explains why they use new technology - peer-to-peer - to retrieve particular songs of which they have already heard - either through word of mouth or, perhaps, through something they read. These opinion leaders do not simply wander aimlessly in search of new music to share with their friends. Rather, 
they listen to many different artists, pay attention to recommendations from friends, and use new technology to find music about which they know something already. Of course, in the absence of information about the size of the students' social networks, we cannot tell whether the range of "word of mouth" activity - recommending and receiving recommendations - is related principally to opinion leadership (maveness) or whether it is the result of simply having a lot of friends (and, of course, the two are highly correlated).

\section{Discussion and conclusion}

Scholars and media pundits alike have hyped the generation of kids who were "born digital" organizing their lives on devices such as cell phones and iPods; flocking to social networking sites like Facebook and MySpace; and, to the alarm of the music industry, downloading music online and shunning traditional CD sales (Hanman, 2005; Palfrey and Gasser, 2008; Swerdlow, 2008). Such commentary would lead one to believe that the majority of young people's music listening activities have moved away from traditional media and are almost exclusively focused on information technologies. Findings in this paper suggest that the situation is more complex. While students certainly get some recommendations about new music through digital media, traditionally important factors such as recommendations from one's social circles and mainstream media continue to be the most important means through which students learn about new music. Our findings are consistent with other literature showing the continued importance of one's social networks in a wired world (Kayahara and Wellman, 2007).

This paper also suggests that people use new technologies to reinforce existing musical habits. On the one hand, it seems that digital media are used by individuals who are heavy music listeners to enrich their experiences by allowing them to browse and search for new music. For these students, browsing the Internet may be akin to turning the radio dial in search of a new song. On the other hand, new technologies are also used by mavens or "trendsetters" to acquire music that they may have learned about through other sources. For these individuals, new technology is not used for browsing as much as it is for retrieving music more expeditiously. Therefore, in addition to showing that new technology is, perhaps, subordinate to social and institutional contexts (personal recommendations and traditional media), we have also found that new technology is not "all one thing." Different types of options afforded by digital media are deployed by different kinds of music users for a variety of purposes. Like other research on the adoption of new technology, this study suggests that technology is a tool used by individuals to enhance existing social and cultural patterns and that there is no predetermined path in the digital age of music.

Finally, we have examined the important role of opinion leaders - or mavens - in the discovery of new music and in the lives of college students more generally. Thirty-four percent of all students in our sample consider themselves mavens, and $16 \%$ recommend music to at least five other people on a regular basis (top mavens). Ninety-five percent say they rely on at least one other person to recommend music to them on a regular basis, underscoring the continued importance of social networks in the music-discovery process. We have also confirmed that opinion leaders in music, as the literature would suggest, are heavily invested in their domain of expertise (e.g., they listen to much more music), they are experimenters and variety-seekers, have diverse tastes and are early adopters (at least in terms of using P2P services). In addition to giving out recommendation, these opinion leaders also receive many recommendations from others. They are immersed in active social networks, exchanging music and recommendations on a regular basis. Unfortunately, we do not have detailed information about the motivation or behavior of such opinion leaders and mavens and how exactly they use new technology like peer- 
to-peer. And, given the limits of our data - our sample cannot be generalized beyond students at elite colleges and our measures of opinion leadership, social exchange, and use of technology are rough proxies - we offer these observations more as conjecture than conclusion.

Theory and evidence from other cultural fields (e.g., fashion) suggest that opinion leadership and status are closely linked. We do not find much evidence for this in our data, due in part, we suspect, to lack of variation in the socio-economic status of the respondents - most of whom come from families where both parents are college graduates. Nonetheless, the increase in access to new music and the availability of new tools to search for and share music will likely have consequences for the social role of opinion leadership and mavens in the future. To date, however, this relationship (among discovery, opinion leadership and status) has largely been ignored by sociologists who have, instead, focused more on existing stocks of cultural capital (knowing and liking accepted forms of culture) rather than on the social processes that lead to discovery and innovation in cultural consumption and to the influence and roles that accompany such exploration and exchange. New technology plays a part in these processes, but certainly not a leading role, at least not yet. The use of technology for discovering new music and culture may become more pervasive in the future; but, based on evidence presented here and historical work on the relationship between technology and culture, we suspect it will be used to reinforce existing social patterns and relationships, rather than transform them.

\section{Acknowledgements}

The authors would like to thank Paul DiMaggio, Gabriel Rossman, Jennifer Lena, David Touve, and two anonymous reviewers for their generous and helpful comments.

\section{Appendix A. Frequencies ${ }^{a}$}

\begin{tabular}{lrr}
\hline & Count & $\%$ \\
\hline Freshman & 75 & 23.4 \\
Sophomore & 104 & 32.5 \\
Junior & 72 & 22.5 \\
Senior & 69 & 21.6 \\
Male & 138 & 42.5 \\
Female & 187 & 57.5 \\
Parents education & & 8.9 \\
$\quad$ No college graduates & 29 & 21.4 \\
$\quad$ One parent is a graduate & 70 & 37.9 \\
$\quad$ Both parents are college graduates & 124 & 31.8 \\
Both parents have graduate degrees & 104 & \\
Time spent online (weekly) & & 23.7 \\
$\quad<3$ h & 78 & 37.8 \\
$4-10$ h & 124 & 38.4 \\
$\quad>10$ h & 126 & 78.4 \\
No omnivore & 258 & 21.6 \\
Yes omnivore & 71 & 81.1 \\
Not a recipient of recommendations & 266 & 18.9 \\
Recipient of recommendations & 62 & \\
\hline This table only includes freguencies & & \\
\hline
\end{tabular}

${ }^{\mathrm{a}}$ This table only includes frequencies for variables not already reported in tables or figures in the body of the paper. 


\section{References}

Anderson, Chris, 2006. The Long Tail. Hyperion, New York.

Arthur, Damien, Sharman, C., Appel, D., Moore, L., 2006. Why young consumers adopt interactive technologies. Young Consumers 7 (3), 33-38.

Atkin, Charles, 1972. Anticipated communication and mass media information seeking. Public Opinion Quarterly 36 (Summer), 188-199.

Bakos, Y., 1998. The emerging role of electronic marketplaces on the Internet. Communications of the ACM 41, 35-42.

Baumgarten, Steven A., 1975. The innovative communicator in the diffusion process. Journal of Marketing Research 12 (February), 12-18.

Bellavance, G., 2008. Where's high? Who's low? What's new? Classification and stratification inside cultural repertoires. Poetics 36 (2-3), 189-216.

Bloch, Peter H., Richins, Marsha L., 1983. A theoretical model for the study of product importance perceptions. Journal of Marketing 47 (Summer), 69-81.

BBC News, 2006. "US File-Sharing Students Targeted." in BBC News, May 2.

Bennett, Andy, 2000. Popular Music and Youth Culture: Music, Identity and Place. Palgrave, London.

Bourdieu, Pierre, 1977. Cultural reproduction and social reproduction. In: Karabel, J., Balsey, A.H. (Eds.), Power and Ideology in Education. Oxford University Press, New York, pp. 487-511.

Bourdieu, Pierre, 1984. Distinction: A Social Critique of the Judgment of Taste. Routledge, London.

Bryson, B., 1997. What about the universe? Musical dislikes and group-based identity construction among Americans with low levels of education. Poetics 25 (2-3), 141-156.

Burns, N., Schlozman, K.L., Verba, S., 2001. The Private Roots of Public Action: Gender, Equality, and Political Participation. Harvard University Press, Cambridge.

Carey, J., 1988. Communication As Culture. Routledge, New York.

Chan, Kenny, Misra, Shekhar, 1990. Characteristics of the opinion leader: a new dimension. Journal of Advertising 19 (3), 53-60.

Clark, Ronald A., Goldsmith, Ronald E., 2005. Market mavens: psychological influences. Psychology \& Marketing 22 (4), 289-312.

Corey, L.G., 1971. People who claim to be opinion leaders: Identifying their characteristics by self report. Journal of Marketing 35, 48-53.

Crane, Diana, 1999. Diffusion models and fashion: a reassessment. The Annals of the American Academy of Political and Social Science 566 (1), 13-24.

DiMaggio, P., 1987. Classification in art. American Sociological Review 52, 440-455.

Doctorow, Cory, 2003. eMusic Turns into a Steaming Pile. BoingBoing.

Emmison, M., 2003. Social class and cultural mobility: reconfiguring the cultural omnivore thesis. Journal of Sociology 39 (3), 211-230.

Engel, J., Kollat, David, Blackwell, Roger, 1968. Consumer Behavior. Hold, Rinchart and Winston, Inc., New York.

Epstein, Jonathon, 1998. Youth Culture: Identity in a Postmodern World. Blackwell, Oxford.

Erickson, B., 1996. Culture, class and connections. American Journal of Sociology 102, 217-251.

Feick, L., Price, L., 1987. The market maven: A diffuser of marketplace information. The Journal of Marketing 51 (1), 8397.

Finnegan, R., 1989. The Hidden Musicians: Music Making in an English Town. Cambridge University Press, Cambridge. Fischer, C.S., 1992. America Calling: A Social History of the Telephone to 1940. University of California Press, Berkeley.

Flynn, L.R., Goldsmith, R.E., Eastman, J.K., 1996. Opinion leaders and opinion seekers: two new measurement scales. Journal of the Academy of Marketing Science 24, 137-147.

Gatignon, H., Robertson, T., 1985. A propositional inventory for new diffusion research. Journal of Consumer Research 11 (March), 849-867.

Gladwell, Malcolm, 2000. The Tipping Point: How Little Things Can Make a Big Difference. Little, Brown and Company, Boston, Mass.

Goldsmith, R.E., Flynn, L.R., Goldsmith, E.B., 2003. Innovative consumer and market mavens. Journal of Marketing Theory and Practice 11, 54-65.

Granovetter, Mark, 1995. Getting a Job: A Study of Contacts and Careers. University of Chicago Press, Chicago.

Grant, A.E., Guthrie, K.K., Ball-Rokeach, S., 1991. Television shopping: a media dependency perspective. Communication Research 18, 773-798.

Hackley, Chris, 2005. Advertising and Promotion: Communicating Brands. Sage Publications, London. 
Hagendoor, Ivar, 2003. The dancing brain. Cerebrum 5 (2), 19-34.

Han, S.K., 2003. Unraveling the brow: what and how of choice in musical preference. Sociological Perspectives 46, 44354459.

Hanman, Natalie, 2005. Growing up with the Wired Generation. The Guardian, November 10.

Hirschman, Elizabeth C., 1980. Innovativeness, novelty seeking and consumer creativity. Journal of Consumer Research 7 (December), 289-295.

Holt, D., 1997. Distinction in America? Recovering Bourdieu's theory of tastes from its critics. Poetics 25 (2-3), 93-120.

Jackson, L.F., 1984. Hierarchic demand and the Engel curve for variety. The Review of Economics and Statistics 66, 8-15.

Katz, Elihu, Lazarsfeld, Paul, 1955. Personal Influence: The Part Played by People in the Flow of Mass Communications. Free Press, Glencoe, Ill.

Katz-Gerro, T., 2006. Comparative evidence of inequality in cultural preferences: gender, class, and family status. Sociological Spectrum 26, 63-83.

Kayahara, J., Wellman, B., 2007. Searching for culture-high and low. Journal of Computer Mediated Communication 12.

Kotarba, J., 2002. Baby boomer rock n roll: fans and the becoming of self. In: Kotarba, J., Johnson, J. (Eds.), Postmodern Existential Sociology. pp. 103-125.

Lin, N., 1999. Social networks and status attainment. Annual Review of Sociology 25, 467-487.

Lizardo, O., 2005. Can cultural capital theory be reconsidered in the light of world polity institutionalism: evidence from Spain. Poetics 33 (2), 81-110.

Loges, W.E., Ball-Rokeach, S., 1993. Dependency relations and newspaper readership. Journalism Quarterly 4, 321-328.

McClary, Susan, 1987. The blasphemy of talking politics during Bach year. In: Leppert, Richard, McClary, Susan (Eds.), Music and Society. Cambridge University Press, Cambridge.

McCracken, G., 1990. Culture and Consumption. Indiana University Press, Bloomington.

Myers, John H., Robertson, Thomas S., 1972. Dimensions of opinion leadership. Journal of Marketing Research 9 (February), 41-46.

Neuman, W. Russell, 1991. The Future of the Mass Audience. Cambridge University Press, New York.

Ollivier, M., van Eijck, K., Warde, A., 2008. Presentation. Poetics 36 (2-3), 115-119.

Palfrey, John, Gasser, Urs, 2008. Born Digital: Understanding the First Generation of Digital Natives. Basic Books, New York.

Peterson, Richard A., Kern, Roger M., 1996. Changing highbrow taste: from snob to omnivore. American Sociological Review 61, 900-907.

Peterson, R.A., Simkus, A., 1992. How musical tastes mark occupational status groups. In: Lamont, M., Fournier, M. (Eds.), Cultivating Differences: Symbolic Boundaries and the Making of Inequality. University of Chicago Press, Chicago, pp. 152-186.

Price, L.L., Feick, L.F., Guskey, A., 1995. Everyday market helping behavior. Journal of Public Policy and Marketing 14, 255-266.

Richins, M., Root-Shaffer, T., 1988. The role of involvement and opinion leadership in consumer word-of-mouth: an implicit model made explicit. Advances in Consumer Research 15, 32-36.

Robertson, Thomas S., Myers, James, 1969. Personality correlates of opinion leadership and innovative buying behavior. Journal of Marketing Research 6 (May), 164-168.

Robertson, Thomas S., Zielinksi, Joan, Ward, Scott, 1984. Consumer Behavior. Scott, Foresman, Glenview, Il.

Rogers, E., 1995. Diffusion of Innovations. Free Press, New York.

Rubin, A.M., 1994. Media uses and effects. A uses and gratifications perspective. In: Bryant, J., Zillman, D., Hillsdale, (Eds.), Media Effects: Advances in Theory and Research. Lawrence Erlbaum Associates, Inc., New Jersey, pp. 417436.

Ruggiero, Thomas E., 2000. Uses and gratifications theory in the 21st century. Mass Communication \& Society 3, 3-37.

Ruvio, A., Shoham, Aviv, 2007. Innovativeness, exploratory behavior, market mavenship, and opinion leadership: an empirical examination in the Asian context. Psychology and Marketing 24 (8), 703-722.

Schudson, Michael, 1986. Advertising, the Uneasy Persuasion: Its Dubious Impact on American Society. Basic, New York.

Sullivan, O., Katz-Gerro, T., 2007. The omnivore thesis revisited: voracious cultural consumers. European Sociological Review 23 (2), 123-137.

Summers, John O., 1970. The identity of women's clothing fashion opinion leaders. Journal of Marketing Research 7 (May), 178-185.

Schwartz, Barry, 2004. Paradox of Choice: Why More Is Less. Ecco, New York.

Schwartz, Barry, 2008. Can there every be too many flowers blooming. In: Tepper, Ivey, (Eds.), Engaging Art: The Next Great Transformation of America's Cultural Life. Routledge, New York. 
Smith, K., Christakis, N., 2008. Social networks and health. Annual Review of Sociology 34, 405-429.

Swerdlow, Joel, 2008. Audiences for the arts in the age of electronics. In: Tepper, Ivey, (Eds.), Engaging Art: The Next Great Transformation of America's Cultural Life. Routledge, New York.

Tian, K.T., Bearden, W.O., Hunter, G.L., 2001. Consumers' need for uniqueness: scale development and validation. Journal of Consumer Research 28, 50-66.

TNS Media Intelligence, 2006. TNS Media Intelligence Reports U.S. Advertising Market Grew 4.1 Percent in First Half of 2006. TNS Media Intelligence, New York.

Upright, C., 2004. Social capital and cultural participation: spousal influence on attendance at arts events. Poetics 31 (1), $129-143$

Van Eijck, K., 2000. Richard A. Peterson and the culture of consumption. Poetics 28, 207-224.

Van Rees, K., Vermunt, J., Verboord, M., 1999. Cultural classifications under discussion: latent class analysis of highbrow and lowbrow reading. Poetics 26, 349-365.

Warde, A., Martens, L., Olsen, W., 1999. Consumption and the problem of variety: cultural omnivorousness, social distinction and dining out. Sociology 33 (2), 105-124.

Warde, A., Wright, D., Gayo-Cal, M., 2008. The omnivorous orientation in the U.K. Poetics 36 (2-3), 148-165.

Wynne, D., O’Connor, J., 1998. Consumption and the postmodern city. Urban Studies 35, 841-864.

Wood, J.T., 2005. Gendered Lives: Communication, Gender And Culture, 6th ed. Wadsworth, Belmont, CA.

Steven J. Tepper is associate director of the Curb Center for Art, Enterprise and Public Policy and Assistant Professor of Sociology at Vanderbilt University. His research focuses on cultural participation, cultural conflict, and social conditions for creativity and innovation. He has recently completed a book that examines protest over art, media and entertainment in 70 U.S. cities in the late 1990s.

Eszter Hargittai is associate professor in the department of communication studies at Northwestern University. Her research focuses on the social and policy implications of information technologies with a particular interest in how IT may contribute to or alleviate social inequalities. Her research projects have looked at differences in people's Web-use skills, the evolution of search engines and the organization and presentation of online content, political uses of information technologies, and how IT are influencing the types of cultural products people consume. 